\title{
Factors associated with tuberculosis cases in Semarang District, Indonesia: case-control study performed in the area where case detection rate was extremely low
}

\author{
Sri Ratna Rahayu • Hironobu Katsuyama • Masashi Demura • \\ Midori Katsuyama · Yoko Ota · Hideji Tanii · Tomomi Higashi • \\ Ngakan Putu Djaja Semadi · Kiyofumi Saijoh
}

Received: 19 November 2014/Accepted: 9 December 2014/Published online: 16 April 2015

(C) The Japanese Society for Hygiene 2015

\begin{abstract}
Objectives Indonesia is ranked as the 4th highest contributor to tuberculosis (TB) in the world. Semarang District in Central Java displays extremely low case detection rate (CDR), possibly contributing to the local prevalence of TB.

Methods A case-control study was performed to explore the factors that cause such low CDR. We recruited 129 TB cases and 83 controls that visited the same centers and were not diagnosed with TB.

Results The cases had $7.5 \pm 2.3$ symptoms/person on average, indicating the delay in diagnosis because the controls only displayed $1.0 \pm 1.7$. The multiple logistic regression analysis comparing the cases/controls extracted following factors as a risk to have TB: farmer, close contact with TB patients, ignorance of whether Bacillus Calmette-Guérin (BCG) was accepted or no, smoking, low income, a lot of people living in the same room, irregular hand wash before meals, not wash hands after blow, soil floor, and no sunlight and no ventilation in the house.

Conclusions Neither the cases nor the controls knew the symptoms and how to avoid TB infection, which probably
\end{abstract}

S. R. Rahayu · M. Demura · M. Katsuyama · Y. Ota ·

H. Tanii · T. Higashi $\cdot$ K. Saijoh $(\varangle)$

Kanazawa University School of Medicine, 13-1 Takaramachi, Kanazawa 9208640, Japan

e-mail: saijohk@med.kanazawa-u.ac.jp

H. Katsuyama

Department of Public Health, Kawasaki Medical University, Kurashiki 7011092, Japan

N. P. D. Semadi

Health Department Semarang District, MT Haryono 29,

Ungaran, Semarang, Indonesia caused the delay in diagnosis. It is difficult to change the current living conditions. Thus, the amendment of the community-based education program of $\mathrm{TB}$ seems to be required.

Keywords Tuberculosis - Case detection rate $\cdot$ Risk factors · Indonesia $\cdot$ DOTS

$\begin{array}{ll}\text { Abbreviations } \\ \text { BCG } & \text { Bacillus Calmette-Guérin } \\ \text { CDR } & \text { Case detection rate } \\ \text { CI } & \text { Confidence interval } \\ \text { DOTS } & \text { Directly observed treatment short course } \\ \text { HIV } & \text { Human immunodeficiency virus } \\ \text { MA } & \text { Monovariate analysis } \\ \text { MDR } & \text { Multidrug resistant } \\ \text { MLR } & \text { Multiple logistic regression analysis } \\ \text { TB } & \text { Tuberculosis }\end{array}$

\section{Introduction}

Tuberculosis (TB) is one of the biggest problems throughout the world and a leading cause of death and major public health problem [1]. Many people with TB remain poorly diagnosed or are diagnosed only after long delays. The high burden of undiagnosed TB causes much suffering such as economic hardship and sustained transmission [2-4].

According to Global Tuberculosis Report 2012 [5], Indonesia is ranked as the 4th (0.4-0.5 million) highest contributor to the TB world after India (2.0-2.5 million), China (0.9-1.1 million), and South Africa (0.4-0.6 
million). Since 2000, 22 high burden countries account for $82 \%$ of all estimated incident cases [5].

The diagnosis of TB in Indonesia in 2011 is 807 per 100,000 population and that in Central Java 637 per 100,000 population [6]. The TB case detection rate (CDR) of Central Java Province is estimated to be $56.93 \%$ [7], but among its local districts Semarang displays an extremely low CDR, 19.21\% [8]. National target for TB control strategy in Indonesia, according to the strategic plan of the Ministry of Health from 2010 to 2014, is to reduce the TB prevalence to 224 per 100,000 population. Output targets are to (1) increase the CDR of new cases of smear-positive pulmonary TB from 73 to $90 \%$, (2) reach successful treatment of new cases of smear-positive pulmonary TB to $88 \%$, (3) increase "the percentage of province with CDR above $70 \%$ " to $50 \%$, and (4) increase "the percentage of the province with treatment success rate above $85 \%$ " from 80 to $88 \%$ [9].

To achieve the national targets for controlling TB, some strategies seem to be very important: empowerment in the community; early detection and registration of TB patients; improvement of the quality of directly observed treatment short course (DOTS) services; facing the challenges of TB/ HIV, multidrug-resistant (MDR-TB) and childhood TB; meet the demands of poor and other vulnerable groups in the society [9]. Domain knowledge is very important in the formation of action. In several developing countries, TB patients are perceived to seek late care or avoid care, due to misunderstanding of popular TB etiologies such as sharing utensils, heavy labor, smoking, bewitchment, and hereditary transmission [10-12]. Thus, it seems very important to know the basic knowledge, attitude, and behavior of the people in such a low CDR region to implement TB programs.

In the present study, differences in the basic knowledge, attitude, and behavior were compared among the TB cases registered in 2012 at the health centers in Semarang District and the controls that visited the same health centers and were diagnosed differently.

\section{Methods}

This study was designed to be a case-control study [13] from 2012 January to 2013 October. TB cases (129) were recruited from the cases registered as TB diagnosis at the health centers in Semarang District and $50 \%$ were female. The controls (83) were recruited among those who visited the same health centers and were diagnosed differently, and $52 \%$ were female. The average age of the cases and controls (Mean \pm SD) was $41.2 \pm 15.3$ and $35.7 \pm 11.7$, respectively. This research was approved by the ethical committees of Kanazawa University School of Medicine, Japan, and Diponegoro University School of Medicine, Dr
Kariadi Hospital Semarang, Indonesia, and Semarang State University, Indonesia. All participants approved this research and gave written informed consent.

TB information of the cases

TB cases were sent to the health center from clinics and diagnosed to have TB using physical examination, microscopic examination by Ziehl Neelsen staining, X-ray, etc.

The method of diagnosis, symptoms, and treatment methods were examined. All of them were treated with DOTS properly regardless of having side effects.

Characteristics of the cases and controls

Demographic characteristics such as gender, age, occupation, origin, BCG experience, close contact with TB patients, smoking habit, having pets, and income were examined. The source of TB information (multiple answers) was also examined. Thereafter, differences in living condition and attitudes in daily life were examined.

Knowledge and opinion about TB

The participants were questioned about the symptoms of TB (multiple answers) and the ways to avoid it (multiple answers). Differences in the opinion and attitude against TB between the cases and controls were examined.

Statistical analysis

The difference in the age and numbers of complaint of the cases and controls was estimated using Student's $t$ test. The differences in the frequency of answers between the cases and the controls were estimated by Chi square $\left(\chi^{2}\right)$ test (monovariate analysis, MA). Multiple logistic regression analysis (MLR) with the cases/controls as the dependent variable was utilized with the independent variables using groups classified by characteristics of the cases and controls. All analyses were performed with SPSS ver. 19 (SAS Institute Inc., Cary, NY). In all analyses, $\rho<0.05$ was taken to indicate statistical significance.

\section{Results}

The 129 cases included 65 males and 64 females, respectively, and the average age was $41.2 \pm 15.3$ (Table 1). Although all the cases were registered at the health centers, around $20 \%$ were diagnosed at the different medical facilities (Table 2). Sputum smear was the first choice for diagnosis [1, 14], but 20 cases were diagnosed without any clinical examination. Chest X-ray was utilized for the 
Table 1 Demographic

characteristics of the cases and control
Average age of the case and control (Mean $\pm \mathrm{SD}$ ) was $41.2 \pm 15.3$ and $35.7 \pm 11.7$, respectively, and the difference was significant $(\rho<0.05$,

Students' $t$ test)

${ }^{a}$ Significant difference in the rate of answers between the case and the control $\left(\rho<0.05, \chi^{2}\right.$ test)

b For multiple answer questions, the difference in the rate of each source was examined using $\chi^{2}$ test. The case and control displayed significant differences in all sources $(\rho<0.05)$

\begin{tabular}{|c|c|c|c|c|c|c|c|c|c|}
\hline & \multicolumn{2}{|c|}{ Cases } & \multicolumn{2}{|c|}{ Controls } & & \multicolumn{2}{|c|}{ Cases } & \multicolumn{2}{|c|}{ Controls } \\
\hline & $N$ & $\%$ & $N$ & $\%$ & & $N$ & $\%$ & $N$ & $\%$ \\
\hline Total & 129 & & 83 & & Smoking & & & & \\
\hline Gender & & & & & No & 41 & 32 & 34 & 41 \\
\hline Male & 65 & 50 & 40 & 48 & No, but family smokes & 45 & 35 & 28 & 34 \\
\hline Female & 64 & 50 & 43 & 52 & Yes & 44 & 34 & 21 & 25 \\
\hline Occupation $^{\mathrm{a}}$ & & & & & Pet & & & & \\
\hline Farmer & 101 & 78 & 31 & 37 & Yes & 67 & 52 & 34 & 41 \\
\hline Others & 28 & 22 & 52 & 63 & No & 62 & 48 & 49 & 59 \\
\hline Education $^{\mathrm{a}}$ & & & & & Income $^{a}$ & & & & \\
\hline Elementary school & 38 & 29 & 8 & 10 & $<100$ & 96 & 74 & 38 & 46 \\
\hline Jr high school & 59 & 46 & 32 & 39 & $100-150$ & 19 & 15 & 31 & 37 \\
\hline High school or higher & 32 & 25 & 43 & 52 & $>150$ & 14 & 11 & 14 & 17 \\
\hline \multicolumn{10}{|l|}{ Origin } \\
\hline Rural & 106 & 82 & 70 & 84 & \multicolumn{5}{|c|}{ Source of TB information (multiple answers) } \\
\hline Urban & 23 & 18 & 13 & 16 & Broadcast $^{\mathrm{b}}$ & 74 & 57 & 64 & 77 \\
\hline Have you ever had BCG? & & & & & Billboards $^{\text {b }}$ & 10 & 8 & 20 & 24 \\
\hline Yes & 33 & 26 & 46 & 55 & Newspaper $^{\mathrm{b}}$ & 18 & 14 & 23 & 28 \\
\hline No & 30 & 23 & 21 & 25 & Medical $^{\mathrm{b}}$ & 89 & 69 & 37 & 45 \\
\hline Do not know & 66 & 51 & 16 & 19 & Acquaintance $^{\mathrm{b}}$ & 9 & 7 & 24 & 29 \\
\hline Close contact with $\mathrm{TB}$ pati & ients $^{\mathrm{a}}$ & & & & Teacher $^{\mathrm{b}}$ & 6 & 5 & 25 & 30 \\
\hline Yes & 18 & 9 & 0 & 0 & & & & & \\
\hline No & 111 & 86 & 83 & 100 & & & & & \\
\hline
\end{tabular}

Table 2 The diagnosis method and symptoms

\begin{tabular}{|c|c|c|}
\hline & $N$ & $\%$ \\
\hline \multicolumn{3}{|l|}{ Location of diagnosis } \\
\hline Health center & 101 & 78 \\
\hline Private clinic & 16 & 13 \\
\hline Others & 12 & 9 \\
\hline \multicolumn{3}{|l|}{ Way of diagnosis } \\
\hline No clinical examination & 20 & 16 \\
\hline Smear alone & 39 & 30 \\
\hline Smear, X-ray & 70 & 54 \\
\hline \multicolumn{3}{|c|}{ Symptoms (multiple answers) } \\
\hline Cough with sputum & 125 & 97 \\
\hline Cough $>2 \mathrm{w}$ & 123 & 95 \\
\hline Hemoptysis & 78 & 60 \\
\hline Dyspnea & 86 & 67 \\
\hline Chest pain & 102 & 79 \\
\hline Malaise & 108 & 84 \\
\hline Anorexia & 108 & 84 \\
\hline Weight loss & 101 & 78 \\
\hline Sweat at night & 77 & 60 \\
\hline Subfever $>1$ Mo & 72 & 56 \\
\hline
\end{tabular}

Mantoux test was utilized only in 2 cases. The mean \pm SD of complaints/person was $7.5 \pm 2.3$, whereas that of the controls only $1.0 \pm 1.7(\rho<0.05$, Students' $t$ test $)$ diagnosis of more than half of the cases. Long-lasting cough with sputum was the most common symptom that was followed by chest pain, malaise, anorexia, and weight loss. Around two-thirds displayed hemoptysis, dyspnea, sweat at night, and long-lasting subfever at night. The cases had many symptoms, $7.5 \pm 2.3$ complaints/person on average. These cases were registered; hence, all of them underwent treatment, whether they knew it was under DOTS or not (Table 3). Nine had no supervisors and at least one-fourth had to pay treatment fee, suggesting that they were not under DOTS. More than $85 \%$ of the cases quit taking medicine at 6 months, regardless of the frequency of medication in the first 2 months. Treatment with 4 drugs was most common, but that with 2 drugs was also observed in around $15 \%$ of the cases. Sputum smear was the most common examination during treatment followed by chest X-ray.

The controls were selected from people who visited the same health center and diagnosed as not having TB. We tried to obtain age- and gender-matched controls. We could achieve gender-matched controls, but their age was slightly lower than the cases (Table 1). Around $80 \%$ of the cases were farmers and around $30 \%$ of them had graduated from elementary school alone. More than half of the controls had received $\mathrm{BCG}$, whereas more than half of the cases did not 
Table 3 Information related to treatments of the cases

\begin{tabular}{ll}
\hline$N$ & $\%$ \\
\hline
\end{tabular}

Was treatment made under DOTS?

$\begin{array}{lrr}\text { Yes } & 80 & 62 \\ \text { No } & 14 & 11 \\ \text { Do not know } & 35 & 27 \\ \text { Who was the supervisor? }^{\mathrm{a}} & & \\ \text { Family } & 86 & 67 \\ \text { Medical Service } & 67 & 7 \\ \text { None } & 9 & \end{array}$

Was treatment free of charge?

$\begin{array}{lll}\text { Yes } & 80 & 62 \\ \text { No } & 33 & 26 \\ \text { Do not know } & 16 & 12\end{array}$

How long was the duration of treatment?

$\begin{array}{lrl}<6 \mathrm{Mo} & 7 & 5 \\ 6 \mathrm{Mo} & 112 & 87 \\ >6 \mathrm{Mo} & 10 & 8\end{array}$

How frequent do you take medication within the first $2 \mathrm{Mo}$ ?

$\begin{array}{lll}\text { Everyday } & 80 & 62 \\ 1 \mathrm{x} / \text { week } & 35 & 27 \\ \text { Longer } & 14 & 11\end{array}$

How many kinds of drugs did you take?

$\begin{array}{lcl}2 & 19 & 15 \\ 3 & 34 & 26 \\ 4 & 70 & 54 \\ 5 & 6 & 5\end{array}$

Did you suffer from side effects?

$+\quad 70 \quad 54$

Which examinations were utilized during treatment $?^{\mathrm{b}}$

$\begin{array}{lrl}\text { Sputum smear } & 104 & 81 \\ \text { Chest X-ray } & 79 & 61 \\ \text { Sputum culture } & 11 & 8.5 \\ \text { Mantoux test } & 11 & 8.5\end{array}$

Distance to the health center

\begin{tabular}{lll}
$\leq 5 \mathrm{~min}$ & 85 & 66 \\
$\leq 30 \mathrm{~min}$ & 21 & 16 \\
Longer & 26 & 18 \\
\hline
\end{tabular}

a 35 cases were supervised both by family and medical staff

b 76 cases were subjected to more than two examinations

know whether they received BCG or not. Nine percent of the cases experienced close contact with TB patients, but none of the controls did. The income of the cases was significantly lower than that of the controls, and threefourths of them got less than $100 \$ /$ month. The cases had already been diagnosed, and hence they obtained more TB information from the medical staff than the controls, but they usually did not use other sources (Table 1). When the living conditions were compared, all conditions were significantly different between the cases and the controls
Table 4 Comparison of living conditions of the participants

\begin{tabular}{|c|c|c|c|c|}
\hline & \multicolumn{2}{|c|}{ Cases } & \multicolumn{2}{|c|}{ Controls } \\
\hline & $N$ & $\%$ & $N$ & $\%$ \\
\hline \multicolumn{5}{|c|}{ Number of persons in the same room ${ }^{\mathrm{a}}$} \\
\hline 1 & 15 & 12 & 10 & 12 \\
\hline 2 & 84 & 65 & 72 & 87 \\
\hline$>3$ & 30 & 23 & 1 & 1 \\
\hline \multicolumn{5}{|l|}{ House floor ${ }^{a}$} \\
\hline Soil & 35 & 27 & 2 & 2 \\
\hline Plaster & 49 & 38 & 18 & 22 \\
\hline Ceramics & 45 & 35 & 63 & 76 \\
\hline \multicolumn{5}{|c|}{ Location of kitchen ${ }^{\mathrm{a}}$} \\
\hline Outside & 51 & 40 & 60 & 72 \\
\hline Inside & 78 & 60 & 23 & 28 \\
\hline \multicolumn{5}{|c|}{ Fuel for cooking ${ }^{a}$} \\
\hline Cordwood & 52 & 40 & 8 & 10 \\
\hline Gas & 77 & 60 & 75 & 90 \\
\hline \multicolumn{5}{|c|}{ Window in each room ${ }^{a}$} \\
\hline Yes & 52 & 40 & 8 & 10 \\
\hline No & 77 & 60 & 75 & 90 \\
\hline \multicolumn{5}{|c|}{ Open windows every day ${ }^{\mathrm{a}}$} \\
\hline Yes & 43 & 33 & 60 & 72 \\
\hline No & 86 & 67 & 23 & 28 \\
\hline \multicolumn{5}{|c|}{ Sunlight into the house $\mathrm{a}^{\mathrm{a}}$} \\
\hline Yes & 66 & 51 & 76 & 92 \\
\hline No & 63 & 49 & 7 & 8 \\
\hline \multicolumn{5}{|c|}{ Ventilation in every room ${ }^{\mathrm{a}}$} \\
\hline Yes & 50 & 39 & 75 & 90 \\
\hline No & 79 & 61 & 8 & 10 \\
\hline \multicolumn{5}{|c|}{ Humidity in the house ${ }^{a}$} \\
\hline Humid & 84 & 65 & 17 & 20 \\
\hline Not humid & 45 & 35 & 66 & 80 \\
\hline
\end{tabular}

(Table 4). "Ceramic floor", "outside kitchen", "gas for cooking", "open windows every day", "sunlight into the house", and "ventilation in every room" were more common in the controls, whereas "window in each room" and high "humidity in the house" were common in the cases.

The cases less frequently "washed their hands before eating", but more frequently "shared their dishes with others" and "drunk from the same glasses/bottles" than the controls (Table 5). They also less frequently "washed their hands after nose blowing" than the controls, whereas no difference was observed in the frequency of whether "they worked when they felt unwell" between these two groups.

To clarify what kinds of physical factors were the most affected differences in the cases and the controls, the MLR was applied (Table 6). The cases/controls were the dependent variables and the groups divided by the above- 
mentioned information were used as determinants. The method of obtaining TB information was removed from the determinant, because that from the cases was modified as described above. The obtained risks were "farmers", "close contact with TB patients", "whether or not they did not know they received BCG", "smoking", and "low

Table 5 The differences in attitudes between the participants

\begin{tabular}{lllll}
\hline & Cases & & \multicolumn{2}{l}{ Control } \\
\cline { 2 - 4 } \cline { 5 - 6 } & & & $N$ & $\%$ \\
\hline
\end{tabular}

Do you wash your hands before eating ${ }^{\mathrm{a}}$

$\begin{array}{lrrrr}\text { Yes } & 45 & 35 & 63 & 76 \\ \text { Sometimes } & 72 & 56 & 18 & 22 \\ \text { No } & 12 & 9 & 2 & 2\end{array}$

Do you eat from the same dish with others? ${ }^{\mathrm{a}}$

$\begin{array}{lrrrr}\text { Yes } & 11 & 9 & 8 & 10 \\ \text { Sometimes } & 86 & 67 & 28 & 33 \\ \text { No } & 32 & 25 & 47 & 57\end{array}$

Do you drink from the same glasses/bottles with others?

$\begin{array}{lrrrr}\text { Yes } & 7 & 5 & 9 & 11 \\ \text { Sometimes } & 92 & 71 & 35 & 42 \\ \text { No } & 30 & 23 & 39 & 47\end{array}$

Do you wash your hands after blowing nose? ${ }^{\mathrm{a}}$

$\begin{array}{lllll}\text { Yes } & 25 & 19 & 40 & 48 \\ \text { Sometimes } & 69 & 53 & 32 & 39 \\ \text { No } & 35 & 27 & 11 & 13\end{array}$

Do you work when you are unwell?

$\begin{array}{lllll}\text { Yes } & 23 & 18 & 25 & 30 \\ \text { Sometimes } & 78 & 60 & 40 & 48 \\ \text { No } & 28 & 22 & 18 & 22\end{array}$

${ }^{a}$ Significant difference between the cases and the controls $(\rho<0.05$, $\chi^{2}$ test)

Table 6 Multiple logistic regression analysis using case/control as the dependent valuable and living status as determinants

Source of TB information (multiple answers) was excluded because this information was modified by consultation of the cases to the health center. Among determinants, age class, gender, education, pet, sharing the dishes, drinking from the same bottle/glass, location of kitchen, fuel for cooking, opening the window every day, and humidity in the house were not selected income "100 \$/month". "High income "150 \$/month" was also extracted as a risk compared with "middle income 100-150 \$/month". To "wash hands before eating", "wash hands after nose blowing" and "not work when unwell" were protective. Among living conditions, "live with more than 3 person in the same room", "soil floor"; no "sunlight in the house" and no "ventilation in the house" were extracted as risk.

Regardless of many symptoms, the cases did not always display significant differences with the controls regarding what they thought were TB symptoms (Fig. 1). "Longlasting subfever" alone was significantly greater in the controls.

More than $70 \%$ of both the cases and the controls thought that it was important to "cover mouth/nose when someone sneezed" (Fig. 2). More than half of the controls thought that "avoiding sharing dishes", "avoiding drinking from the same glass/bottle", "washing hands after touching items in the public" and "maintaining good nutrition" were the ways to avoid getting TB and the rates were significantly higher than the cases. In fact, $76 \%$ of the controls washed hands before eating and only $35 \%$ of the cases did so (Table 5). Moreover, $76 \%(9+67)$ of the cases at least sometimes "shared their dishes" and "drank from the same glass", which was significantly higher than the controls. On the other hand, $87 \%(39+48)$ of the controls at least sometimes "washed hands after blowing nose". "Vaccination" was also higher in the controls than in the cases (Fig. 2).

Opinions related to the seriousness and shame did not display any significant difference between the cases and the controls (Table 7). Although many of the cases and controls thought TB to be "serious", they did not always think that TB was "serious at workplaces" and "affected work performance". Significant difference was not observed in

\begin{tabular}{llllrll}
\hline & Comparison & Reference & Odds & \multicolumn{2}{c}{ P5 \% CI } \\
\hline Occupation & Workers & Farmers & 0.05 & $<0.01$ & 0.00 & 0.20 \\
& Others & Farmers & 0.05 & 0.01 & 0.00 & 0.54 \\
Close contact with TB patients & No & Yes & 0.00 & 0.02 & 0.00 & 0.49 \\
BCG & Yes & Do not know & 0.04 & $<0.01$ & 0.00 & 0.32 \\
Smoking & No & Yes & 0.14 & 0.04 & 0.01 & 0.92 \\
Income $(\$ / M o)$ & $100-150$ & $<100$ & 0.05 & $<0.01$ & 0.00 & 0.33 \\
& $100-150$ & $>150$ & 0.08 & 0.04 & 0.01 & 0.89 \\
Person/room & 1 & $\geq 3$ & 0.00 & $<0.01$ & 0.00 & 0.35 \\
& 2 & $\geq 3$ & 0.00 & $<0.01$ & 0.00 & 0.27 \\
Wash hands before eating & Yes & Sometimes & 0.06 & $<0.01$ & 0.01 & 0.32 \\
Wash hands after blowing nose & Sometimes & No & 0.06 & 0.01 & 0.01 & 0.46 \\
Work when unwell & No & Yes & 0.09 & 0.02 & 0.00 & 0.66 \\
Floor & Ceramics & Soil & 0.06 & 0.04 & 0.00 & 0.90 \\
Sunlight in the house & Yes & No & 0.06 & 0.02 & 0.00 & 0.67 \\
Ventilation in the house & Yes & No & 0.02 & $<0.01$ & 0.00 & 0.24 \\
\hline
\end{tabular}


Fig. 1 Differences in the knowledge about TB symptoms between the cases and controls (multiple answers). Asterisk significant differences $\left(\rho<0.05, \chi^{2}\right.$ test and Student's $t$ test)

Fig. 2 Differences in the way that the cases and controls thought was good to avoid getting TB. Asterisk significant differences $\left(\rho<0.05, \chi^{2}\right.$ test $)$
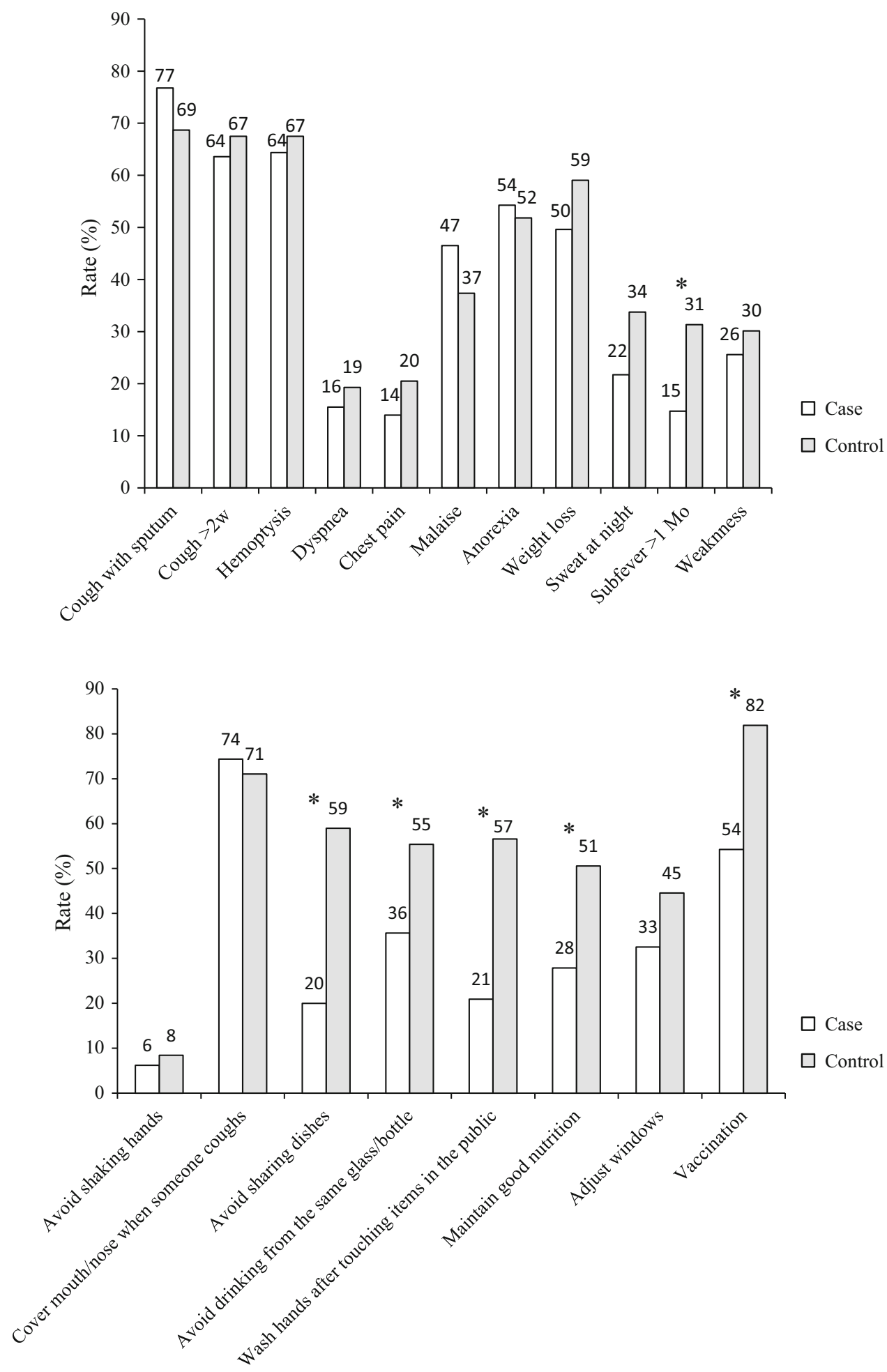

"being ashamed of having TB", but the cases tended to want to "hide having TB". Significantly more controls thought "TB affected relationship with others" and "wanted to be isolated", whereas there was no significant difference in "TB affecting family responsibility" against the controls. Both of the cases and controls usually tried to be good to TB patients. Around $50 \%$ of the controls believed that "TB treatment was very costly", but around one-fourth of the cases did not think so. "HIV-positive people's concern about TB" was significantly higher in the controls than in the cases. Around one-fourth to one-third of the cases and controls believed that TB was hereditary. 
Table 7 Differences in the opinion against TB between the cases and controls

\begin{tabular}{lllll}
\hline & Cases & & & Controls \\
\cline { 2 - 3 } \cline { 5 - 6 } & $N$ & & $N$ & $\%$ \\
\hline
\end{tabular}

Do you think that TB is serious?

Yes
No not know

91
2
36

71

2

Do you think that TB is serious at workplaces?

$\begin{array}{lllll}\text { Yes } & 46 & 36 & 34 & 41 \\ \text { No } & 14 & 11 & 10 & 12 \\ \text { Do not know } & 69 & 53 & 39 & 47\end{array}$

Does TB affect your work performance?

$\begin{array}{ll}\text { Yes } & 51 \\ \text { Not always } & 60 \\ \text { No } & 18\end{array}$

$\begin{array}{lll}40 & 43 & 52\end{array}$

$\begin{array}{lll}47 & 29 & 35\end{array}$

Do you feel ashamed of having TB?

$\begin{array}{ll}\text { Yes } & 49 \\ \text { No } & 53 \\ \text { Do not know } & 27\end{array}$

Do you want to hide having TB? ${ }^{\mathrm{a}}$

$\begin{array}{lllll}\text { Yes } & 14 & 11 & 10 & 12 \\ \text { Not always } & 74 & 57 & 30 & 36 \\ \text { No } & 41 & 32 & 43 & 52\end{array}$

Does TB affect your relationship with others? ${ }^{\mathrm{a}}$

$\begin{array}{ll}\text { Yes } & 20 \\ \text { Not always } & 72 \\ \text { No } & 37\end{array}$

Does TB affect family responsibilities?

$\begin{array}{ll}\text { Yes } & 58 \\ \text { Not always } & 53 \\ \text { No } & 18\end{array}$

16

56

29

$\begin{array}{ll}36 & 44 \\ 35 & 42 \\ 12 & 14\end{array}$

Do you want to live isolated due to having TB? ${ }^{\mathrm{a}}$

$\begin{array}{lrrrr}\text { Yes } & 5 & 4 & 12 & 14 \\ \text { Not always } & 43 & 33 & 25 & 30 \\ \text { No } & 81 & 63 & 46 & 55\end{array}$

How do you feel about a person with TB?

Desire to help 94

Want to stay away 28

No particular feeling

73

$73 \quad 59$

22

$59-71$

20

4

24

5

Is TB treatment very costly? ${ }^{\mathrm{a}}$

$\begin{array}{lllll}\text { Yes } & 32 & 25 & 42 & 51 \\ \text { Not always } & 44 & 34 & 21 & 25 \\ \text { No } & 53 & 41 & 20 & 24\end{array}$

Do you think that HIV-positive people should be concerned about TB? ${ }^{\mathrm{a}}$

$\begin{array}{lllll}\text { Yes } & 23 & 18 & 39 & 47 \\ \text { Not always } & 79 & 61 & 30 & 36 \\ \text { No } & 27 & 21 & 14 & 17\end{array}$

Do you think that TB is hereditary

$\begin{array}{lllll}\text { Yes } & 30 & 23 & 24 & 29 \\ \text { No } & 79 & 61 & 47 & 57 \\ \text { Do not know } & 20 & 16 & 12 & 14\end{array}$

o not know a Significant difference between the cases and the controls $\left(\rho<0.05, \chi^{2}\right.$ test $)$ 


\section{Discussion}

In Indonesia, regular health examination is not mandatory [6]. Therefore, after symptoms became apparent, the person visited the clinic where sputum smear was not always available. The cases in the present study displayed $7.5 \pm 2.3$ complaints/person on average, indicating the delay of diagnosis [15]. Although early diagnosis and initiation of treatment of infectious cases are the best measures to reduce transmission $[3,16,17]$, in some countries $20 \%$ of patients were not diagnosed for over 6 months from the onset of symptoms [18]. Even after the symptoms became obvious, it took at least 2 more days for diagnosis, because positive TB was defined as more than 2 positive sputum smears in the smear performed three times within 2 days [14]. Household contacts continued meantime, when patients were with potentially infectious forms proceeding to high prevalence of TB $[19,20]$. On the other hand, culture was not common, whereas patients with smear-negative, culture-positive TB were reportedly responsible for TB transmission [21, 22]. Immediate introduction of culture examination is required because, in addition to high sensitivity, it allows determining whether the patient is sensitive to anti-TB drugs and useful for finding extrapulmonary TB [14].

The cases did not always know whether they were under DOTS treatment or not, but all the cases could luckily quit taking medicine regardless of the obvious delay of diagnosis. Around $80 \%$ of the cases were farmers and around $30 \%$ had graduated from elementary school alone; hence, their income was lower than the controls. Low income and low education are reportedly associated with TB infection [4, 23-25]. They also had lost the chance of BCG injection. This occupation was also extracted as a risk by the MLR. However, the MLR extracted high income as a risk as well. Such a result is not always in accordance with several studies [4, 23-25], whereas it is conceivable that people with high income, regardless of their occupation, have more chances to live and/or work at places with a lot of people where a risk of TB transmission is supposed to be high. The number was small, but only cases had a chance of close contact with TB patients. TB contact was absolutely a risk factor for TB transmission [18, 26]. No significant difference was found in the rate of "smoking" by the MA, but the MLR extracted "smoking" as a risk. This is in good accordance with a previous report [23]. It is natural that the "source of TB information" of cases was medical staff, but the cases were not always eager to collect information from other sources compared with the controls. All the items related to living condition were significantly different between the cases and the controls according to the MA. Among them, the MRL extracted "small number of persons in a room", "ceramic floor", "sunlight in the house", and "ventilation in the house" as protective. The importance of good ventilation has been emphasized elsewhere $[3,23]$. Excluding "work when unwell", their attitudes displayed significant differences between the cases and the controls by the MA. "Share the dish" and "drink from the same glasses/bottles" were not extracted by the MLR. Instead, "work when unwell" was extracted as well as "wash hands before eating" and "wash hands after nose blowing". These findings may be a reflection that TB is airborne. In general, the cases were not aware of the danger in their attitudes, which was in good accordance with previous reports [10-12].

Both the cases and the controls did not recognize "dyspnea" and "chest pain" as TB symptoms. Significant differences existed, but "long-lasting subfever" was also not considered as TB symptoms. "dyspnea", "chest pain," and "long-lasting subfever" were less frequent than "cough with sputum", "malaise", and so on, but a number of cases complained of these. Thus, it seems necessary make people aware of TB symptoms [10-12].

TB itself was recognized to be dangerous both by the cases and the controls, but they did not recognize its dangerousness at work places. Many of the cases were farmers; hence, it seems less possible to spread TB than workers. However, TB-positive workers can work and be able to transmit TB to their colleagues. On comparing the rate of both the cases and controls who thought "having TB was a shame", the rate of "wanted to hide having TB" was less. It seems natural that more controls who did not receive TB treatment believed that TB "affected relationship with others" and wanted to "live isolated in case of TB" than the cases. DOTS performed under the governmental hospitals and health centers were free [9], but some cases visiting private hospitals/clinics had to pay the treatment fee. A higher rate of "HIV-positive people should be concerned about TB" in the control was reflection that they were more eager to collect information than the cases. HIV infection reportedly affected TB infection [27]. However, the number who believed "TB was hereditary" was not different between the two groups.

Some aspects underlying the low coverage CDR are socioeconomic, education/knowledge, and stigma problems [4]. Economic conditions will affect the public in obtaining not only good environmental home conditions, but also an excellent level of education. The level of education in this study was relatively low because many people only finished elementary school where sufficient TB education was impossible. Poor education will cause shortage of knowledge about TB, leading the public into embarrassment and sometimes attitude to hide their disease if they are exposed to TB. Such conditions in some people may cause delay in going to health service [18]. As a result, TB has spread among farmers even when their contact has 
not always been intense like workers. It is very difficult to change occupation, income, and housing conditions immediately. Thus, community-based TB education is very important. It may be useful to educate and expose not only public, but also private practitioners to community-based TB programs $[9,28]$.

Some cases were not dependent on the free DOTS program. To inform about the existence of this program is also good education. Utilization of this program not only reduces multidrug-resistant $\mathrm{TB}$, but also helps reduce outof-pocket expenses to patients [27]. The number of syndromes of the cases absolutely indicates the delay in diagnosis.

The classic symptoms of TB are fever, cough, and weight loss, but they are non-specific and can be mimicked by other conditions, including malignancy and other pulmonary infections. That is, in an early stage, such syndromes are not always specific to TB. However, importance of these classic lung related with syndromes should be aware of that they are possible signs of initiation of TB expansion [29].

Acknowledgments We would like to thank to Semarang State University, Directorate General of Higher Education (DGHE or DIKTI), and Health Department Semarang District for all their support.

Conflict of interest The authors declare that there is no conflict of interests regarding the publication of this paper.

\section{References}

1. WHO. Systematic Screening for active TB. WHO, Geneva 27 Switzerland, 2013.

2. Bauer M, Leavens A, Schwartzman K. A systematic review and meta-analysis of the impact of tuberculosis on health-related quality of life. Qual Life Res. 2013;22:2213-35.

3. Saxena S, Karkhanis V, Joshi JM. Tuberculosis prevention: an enigma worth unravelling. Indian J Tuberc. 2012;59:65-7.

4. Wu J, Dalal K. Tuberculosis in Asia and the pacific: the role of socioeconomic status and health system development. Int J Prev Med. 2012;3:8-16.

5. WHO. Global Tuberculosis Report 2012. WHO, 20 Avenue Appia, 1211-Geneva-27, Switzerland, 2012:11.

6. Ministry of Health, R.I. Current Report of Development of Tuberculosis in Indonesia January-December 2012. Ministry of Health Republic Indonesia: Jakarta, Indonesia, 2012.

7. Ministry of Health, R.o.I. Profile of Health Data of Indonesia in 2011. Ministry of Health of The Republic of Indonesia: Jakarta, Indonesia. 2012.

8. Health Department, S.D. Reported TB Cases in Semarang District, 2011. Semarang District, Central Java, Indonesia. 2011.

9. Ministry of Health, R.O.I, Directorate General of Disease Control and Environmental Health National. Strategy for Controlling TB in Indonesia 2010-2014. Republic of Indonesia Health Ministry Directorate General of Disease Control and Environmental Health, Jakarta, 2011.
10. Notoatmodjo S. Health promotion and behavioral sciences. Jakarta: Rineka Cipta; 2007.

11. Tasnim S, Rahman A, Hoque FM. Patient's Knowledge and Attitude towards Tuberculosis in an Urban Setting. Pulm Med. 2012;2012:352850.

12. Buregyeya E, et al. Tuberculosis knowledge, attitudes and healthseeking behaviour in rural Uganda. Int $\mathrm{J}$ Tuberc Lung Dis. 2011;15:938-42.

13. Raj S. Bhopal, A.B.a.J.U.P.o.P.H., et al. Concepts of Epidemiology, an itegrated introduction to the ideas, theories, principles and methods of epidemiology. 2002, US, New York: Oxford University.

14. Health Minister of The Republic of Indonesia, N.M.S.V. Tuberculosis Control Guidelines. Health Minister of The Republic of Indonesia Jakarta, Indonesia, 2009.

15. Ahmad RA, et al. Diagnostic delay amongst tuberculosis patients in Jogjakarta Province, Indonesia is related to the quality of services in DOTS facilities. Trop Med Int Health. 2011;16:412-23.

16. Dye C. Tuberculosis 2000-2010: control, but not elimination. Int J Tuberc Lung Dis. 2000;4:S146-52.

17. Reid MJ, Shah NS. Approaches to tuberculosis screening and diagnosis in people with HIV in resource-limited settings. Lancet Infect Dis. 2009;9:173-84.

18. Yang YR, et al. Evaluation of the tuberculosis programme in Ningxia Hui Autonomous region, the People's Republic of China: a retrospective case study. BMC Public Health. 2012;12:1110.

19. Batra S, et al. Childhood tuberculosis in household contacts of newly diagnosed TB patients. PLoS One. 2012;7:e40880.

20. Jensen, P.A., Centers for Disease Control and Prevention (US), and National Center for HIV STD and TB Prevention (US), Guidelines for preventing the transmission of Mycobacterium tuberculosis in health-care settings, 2005. MMWR recommendations and reports. 2005, Atlanta, GA: US Department of Health and Human Services, Public Health Service, Centers for Disease Control and Prevention. p 141.

21. Kanaya AM, Glidden DV, Chambers HF. Identifying pulmonary tuberculosis in patients with negative sputum smear results. Chest. 2001;120:349-55.

22. Sarmiento OL, et al. Assessment by meta-analysis of PCR for diagnosis of smear-negative pulmonary tuberculosis. J Clin Microbiol. 2003;41:3233-40.

23. Oxlade O, Murray M. Tuberculosis and poverty: why are the poor at greater risk in India? PLoS One. 2012;7:e47533.

24. Shen $X$, et al. Tuberculosis in an urban area in China: differences between urban migrants and local residents. PLoS One. 2012;7:e51133.

25. Clark M, Riben P, Nowgesic E. The association of housing density, isolation and tuberculosis in Canadian First Nations communities. Int J Epidemiol. 2002;31:940-5.

26. Sacchi FPC, et al. Sugar cane manufacturing is associated with tuberculosis in an indigenous population in Brazil. Trans R Soc Trop Med Hyg. 2013;107:152-7.

27. Ismail I, Bulgiba A. Determinants of unsuccessful tuberculosis treatment outcomes in Malaysian HIV-infected patients. Prev Med. 2013;57:S27-30.

28. Artawan Eka Putra IW, et al. Factors associated to referral of tuberculosis suspects by private practitioners to community health centres in Bali Province, Indonesia. BMC Health Serv Res. 2013;13:445.

29. Davies PDO, Barnes PF, Gordon SB. Clinical tuberculosis. 4th ed. London: Hodder Arnold; 2008. 